\title{
Information System Construction of Spare Parts Supply Based on Supply Chain
}

\author{
Wukui ZHAO ${ }^{a}$, Cheng ZHANG $^{b}$ and Xiang ZHAO ${ }^{c}$ \\ 6th Department, Shijiazhuang Mechanical Engineering College, Shijiazhuang, 050003, China \\ azwksky001@163.com, bzflysky@163.com, czysky508@163.com
}

Keywords: Equipment spare parts, supply chain, information system.

\begin{abstract}
Equipment spare parts in equipment maintenance play an important role in the management, maintenance and repair of damaged equipment. Information system of spare parts supply is constructed based on supply chain. The generic configuration of supply chain is introduced, based on which the information system of spare parts supply is established. The proposed information system includes three levels. The lowest level is spare parts supply entity level which mainly includes all sorts of entities involved in spare parts supply activities. The middle level is spare parts data collecting level which including information resources integrating platform and spare parts information data collecting platform. The highest level is spare parts data releasing level which includes common information platform and management information platform. The optimization of spare parts supply system architecture is also proposed through analyzing the business process of spare parts. The proposed information system architecture provides an effective method and design thought for spare parts supply chain design and optimization.
\end{abstract}

\section{Introduction}

Equipment spare parts in equipment maintenance play an important role in the management, maintenance and repair of troop equipment. They are also the most important material basis to conducting equipment operation and equipment support mission[1]. Equipment operational readiness and combat power are affected directly by equipment spare parts support capability. How to get spare parts in time and economically is one of the keys to fulfill the repair task with great efficiency and speed. Reduce the spare parts stock funds, improve the utilization of spare parts inventory reasonably and effectively is an important content of the contemporary national defense. The traditional pattern of spare parts inventory management has been difficult to meet the needs of equipment maintenance in the modern information war. Supply chain management is an effective method to organize the supplier, manufacturer, storehouse, distribution center and supply channel[2]. It magnifies the matching of resource consolidation and the core capability in order to reduce the cost of supply chain. At the same time, the surveillance of equipment spare parts logistics and the control of equipment spare parts quality are realized. Through this way, the consolidation and optimization of the resources of equipment spare parts logistics are achieved, which provides an information platform for the information transmitting of equipment support management organization. At present literature, effective supply chain practice and effective information sharing are two sources of supply chain improvement[3]. While some companies emphasize improving supply chain practice, others emphasize leveraging the information sharing among supply chain partners. Although supply chain has been used in equipment support to improve the efficiency of spare parts supplying, but the information system has not been constructed systematically and effectively, which confines the application and efficiency of supply chain.

This paper discusses the construction of information system of spare parts supply based on supply chain. The generic configuration of supply chain is introduced firstly. Then, the information system of spare parts supply is established based on supply chain, which includes three levels. At last, the optimization of spare parts supply system architecture is proposed through analyzing the business process of spare parts. 


\section{Supply chain}

Supply chain is the network of suppliers, manufacturer, warehouses, distributors and retailers through which material flow, information flow, and financial flow are acquired, transformed and delivered. Supply chain management and information technology management have attracted much attention from both practitioners and researchers $[4,5]$. As information technology evolves, firms tend to become more integrated. Therefore, integrating effective supply chain practice with effective information sharing becomes critical for improving supply chain performance. Effective supply chain management can optimize the performance of the nodes on the supply chain by optimizing the transfer of goods, information, and services between buyers and suppliers in the value chain, so it become a common strategy adopted in business to improve efficiency. The supply chain has been defined as the network of organizations that are involved, through upstream and downstream linkages, in the different processes and activities that produce value in the form of products and services in the hands of the ultimate customer aim to increase transparency and alignment of the supply chain's co-ordination and configuration, regardless of functional or corporate boundaries. The basic idea of supply chain management is to recognize the interdependency in the supply chain, and thereby improve its configuration and control based on such factors as integration of business processes. The generic configuration of supply chain is showed in Fig.1.

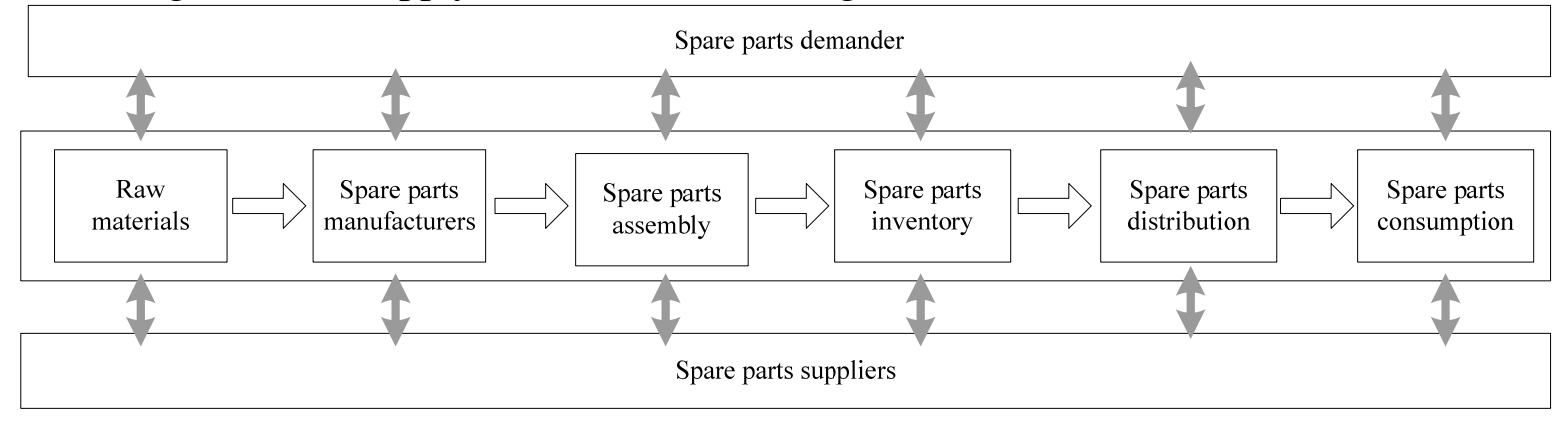

$\longrightarrow$ Materials flow Information flow

Fig. 1 The generic configuration of supply chain

\section{Information system platform construction}

Information system of spare parts supply based on supply chain is to realize the effective information cooperation and interlinkage for the supplier, the demander, the distribution personnel and the store-keeper through information collecting, transmitting, changing and processing in the full process of spare parts logistics including stocking, delivering, storage, distributing using information technology, information platform and information equipment. From the view of client, the information system includes three levels which corresponding to spare parts entity level, spare parts data collecting level and spare parts data releasing level. The logic relationship is showed in Fig. 2.

The established information system of spare parts supply based on supply chain mainly includes two parts from the view of implementation. The first part is spare parts common information platform and the second part is information resources integration and data collecting platform of spare parts. The information system platform provides service for spare parts entities including spare parts management organization, spare parts manufacturer, spare parts supplier and logistics organization, etc. These clients can receive spare parts information based on information resources integrating platform and spare parts information data collecting platform, through which the control information and information circulation of spare parts can be achieved. The collected spare parts information can be processed by relative module of information resources integrating platform and spare parts information data collecting platform. The processed data information can be uploaded to the common information platform and released as share information if these data information be treated as share information. Then these data information can be served as the inquiring information for manufacturer, supplier and clients freely or with authorization. 


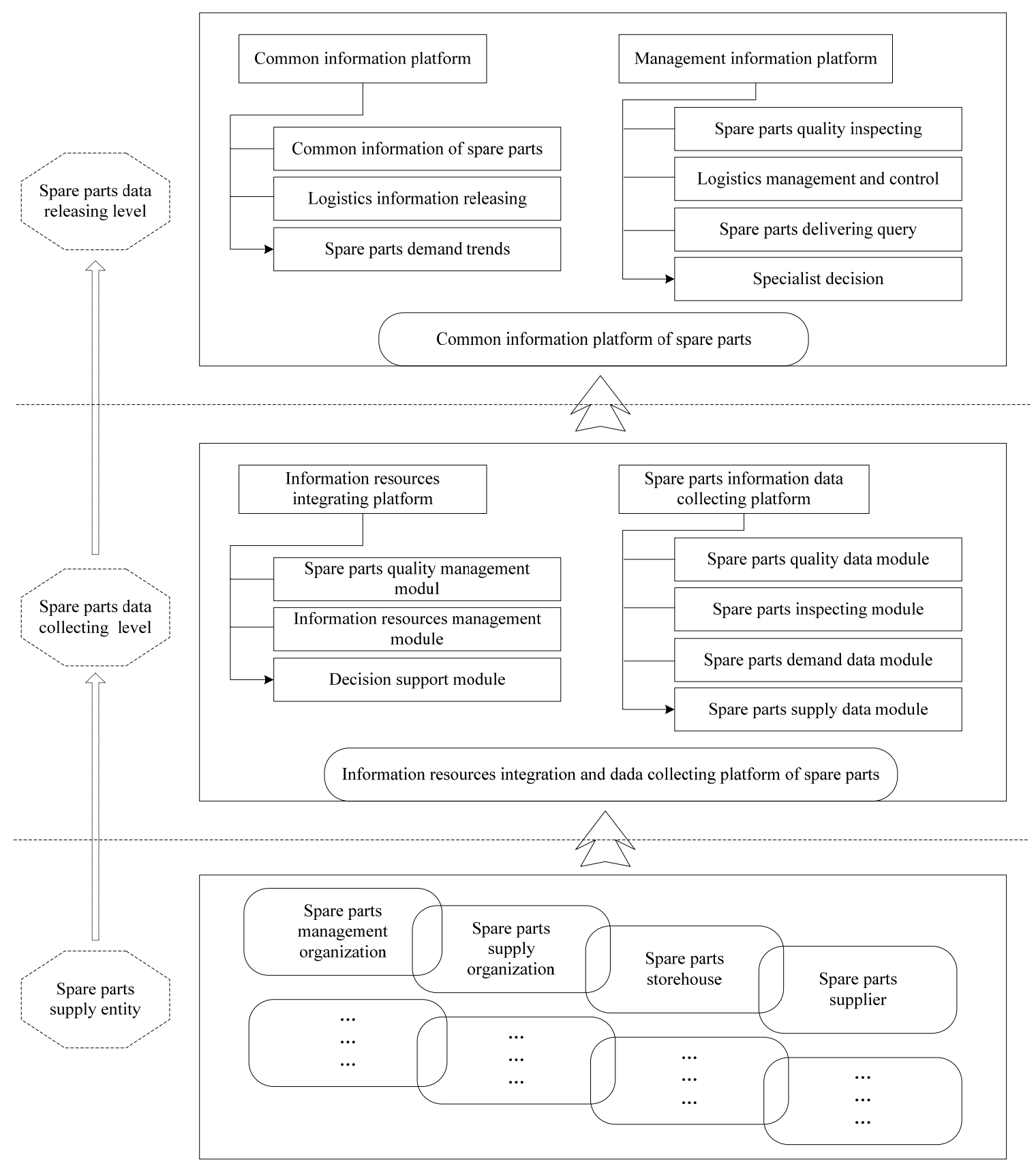

Fig. 2 The architecture of spare parts information system platform

\section{Spare parts supply system architecture optimization}

With the fast development of information technology, information has become an important element to form combat capability as well as in equipment spare parts supply process. The goal of constructing spare parts information system is to provide spare parts information to various personnel or organization through effective information management. The optimization of spare parts information system architecture to realize the full information flow process from spare parts manufacture, sale, repertory, delivering, transmitting to consumption is an effective way to improve the efficiency of spare parts supply. The optimization of spare parts information architecture can be established through analyzing the business process of spare parts as indicated in Fig.3.

All sorts of spare parts information can be transmitted smoothly through integrating information of each business system and breaking system confines. The proposed optimization model can be realized by constructing spare parts supply chain circulating management platform, which provides basis for business management such as spare parts manufacturing, repertory, delivering, etc. 


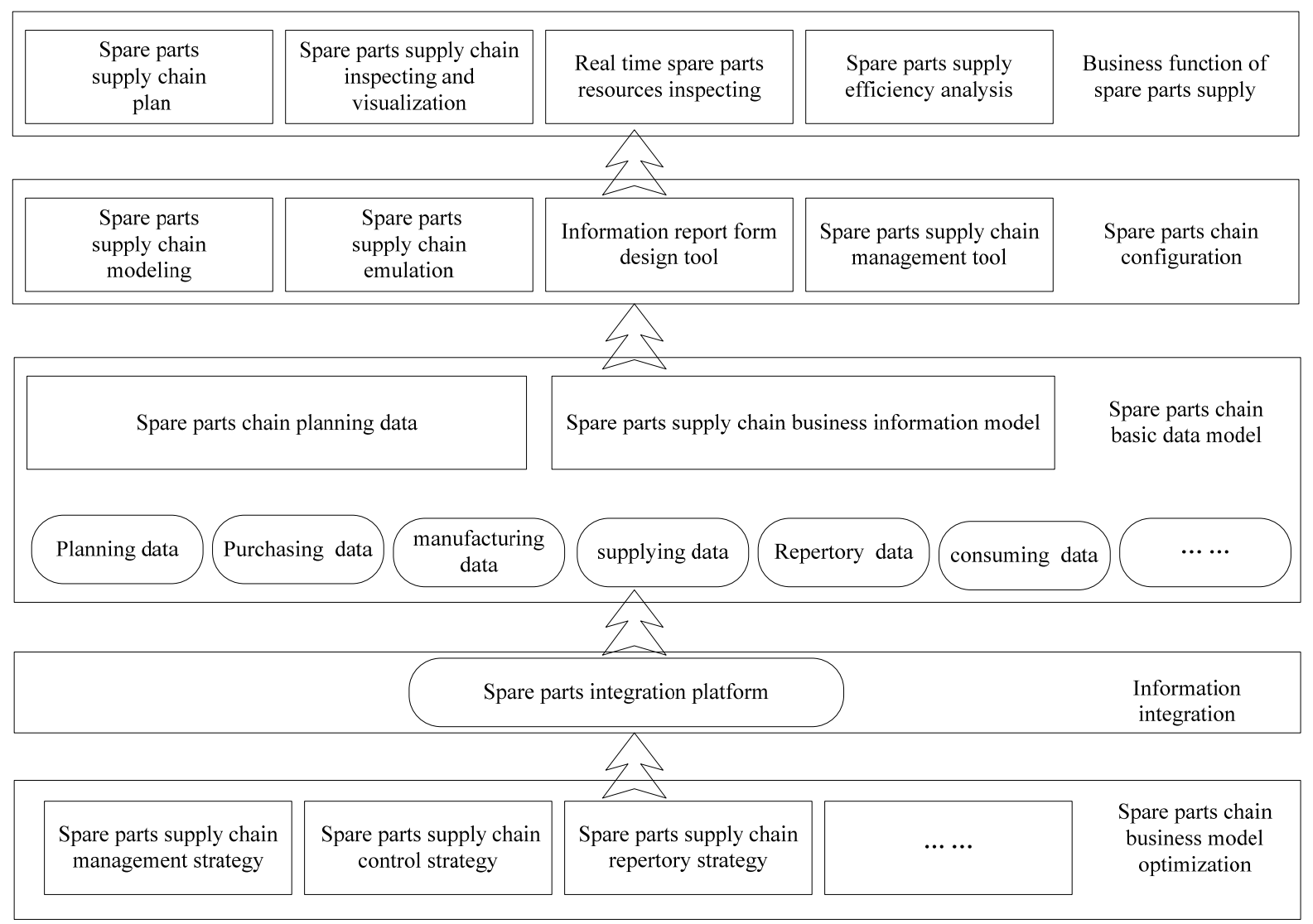

Fig.3 The optimization process of spare parts supply system architecture

\section{Summary}

Equipment spare parts in equipment maintenance play an important role in the management, maintenance and repair of damaged equipment. Information system of spare parts supply is constructed based on supply chain. The generic configuration of supply chain is introduced, based on which the information system of spare parts supply is established, which includes spare parts supply entity level, spare parts data collecting level and spare parts data releasing level. The core of the proposed information system is the common information platform and management information platform. The optimization of spare parts supply system architecture is also proposed through analyzing the business process of spare parts, which provides an effective method and design thought for spare parts supply chain design and optimization.

\section{References}

[1] H. J. Zhu, J. Chen, Research on forecast model of equipment maintenance spare part requirement, Ship Electronic Engineering, 9(2010) 147-149.

[2] R. Vrijhoef, L. Koskela, The four roles of supply chain management in construction, European Journal of Purchasing \& Supply Management, 6 (2000) 169-178.

[3] A. Agarwal, R. Shankar, M. K. Tiwari. Modeling agility of supply chain, Industrial Marketing Management, 36 (2007) 443-457.

[4] H. G. Zhou, W.C. Benton Jr, Supply chain practice and information sharing, Journal of Operations Management, 25 (2007) 1348-1365.

[5] D. J. Closs, D. A. Mollenkopf, A global supply chain framework. Industrial Marketing Management, 33 (2004) 37-44. 